\title{
A novel plasmid from Staphylococcus epidermidis specifying resistance to kanamycin, neomycin and tetracycline
}

\author{
S. SCHWARZ, P. D. GREGORY*, CHRISTIANE WERCKENTHIN, S. CURNOCK* and K. G. H. DYKE* \\ Institut für Kleintierforschung Celle/Merbitz der Bundesforschungsanstalt für Landwirtschaft Braunschweig- \\ Völkenrode (FAL), Dornbergstr. 25-27, 29223 Celle, Germany and * Microbiology Unit, Department of \\ Biochemistry, University of Oxford, South Parks Road, Oxford OX1 $3 Q U$.
}

\begin{abstract}
The naturally occurring plasmid pSTS7 from Staphylococcus epidermidis mediated resistance to tetracycline via a tet $\mathrm{L}$ gene and to kanamycin and neomycin via an aadD gene. Plasmid pSTS7 showed partial restriction map and sequence homology to the previously described tetracycline resistance plasmid pNS1981 from Bacillus subtilis and to the kanamycin/neomycin/bleomycin resistance plasmid pUB110 from $S$. aureus. Sequence analysis of the regions flanking the two resistance genes in pSTS7 led to the identification of a novel site for interplasmid recombination which could explain the derivation of pSTS7 from the incompatible pNS1981- and pUB110-like parental plasmids under tetracycline-selective pressure.
\end{abstract}

\section{Introduction}

The use of antibiotics in animals, either as feed additives or for therapeutic and prophylactic purposes, promotes the selection of resistant organisms and the spread of antibiotic resistance genes among bacteria of the same genus, and also to those of different genera $[1,2]$. Previous studies have shown that pathogenic staphylococci from man and animals carry virtually the same antibiotic resistance genes on mobile genetic elements [3-5].

Tetracycline resistance $\left(\mathrm{Tc}^{r}\right)$ plasmids of staphylococci isolated from man and animals belong to a family of structurally closely related plasmids of c. $4.5 \mathrm{~kb}[5,6]$; the prototype plasmid of this family, pT181 from Staphylococcus aureus [7], has been sequenced completely $[8,9]$ and its tetracycline resistance gene has been assigned to the class $\mathrm{K}$ of bacterial tet genes [10]. A second family of $\mathrm{Tc}^{r}$ plasmids identified in staphylococci of animal origin carry a tet $\mathrm{L}$ gene $[6,11]$, are more variable in size, and contain additional resistance genes [6]. Plasmids that carry tet $\mathrm{L}$ genes were isolated originally from various Bacillus species [12-15], but can replicate and express their resistances in staphylococci [11].

Combined resistance to kanamycin and neomycin is mediated by an aminoglycoside adenyltransferase of the type $\operatorname{AAD}\left(4^{\prime}\right)\left(4^{\prime \prime}\right)$, the gene for which, designated aad D, is located on small plasmids of $4.2-4.5 \mathrm{~kb}$ or

Received 11 Sept. 1995; revised version accepted 13 Nov. 1995.

Correspondence should be sent to Dr. S. Schwarz. on larger plasmids of $c .35 \mathrm{~kb}$ [5]. The prototype plasmid of the small aadD-carrying plasmids, pUB110 from $S$. aureus, has been sequenced completely $[16,17]$. Since it replicates at a copy number of 30 $50 /$ cell in $B$. subtilis and expresses its aadD gene in this host, it is used as a cloning vector in $B$. subtilis [16].

The tetL-encoding plasmid pNS1981 from B. subtilis $[13,14]$ and the staphylococcal aadD-encoding plasmid pUB110 [16] are homologous except for the region covered by their resistance genes. The regions flanking the resistance genes contain two junctions [18] thought to be involved in the exchange of the resistance gene cassettes. This study describes a naturally occurring plasmid pSTS7 from $S$. epidermidis isolated from a pig after use of tetracyclines to control exudative epidermitis. Plasmid pSTS7 has considerable homology to the two incompatible plasmids pNS1981 and pUB110, but carries the tet $\mathrm{L}$ gene and the aad $\mathrm{D}$ gene. Sequence analyses were conducted on the regions flanking both resistance genes to determine the areas that served for cointegrate formation. A model is presented to explain how pSTS7 might have evolved from pNS1981- and pUB110-like precursors under the selective pressure of tetracycline use.

\section{Materials and methods}

Bacteria, plasmids and resistance testing

$S$. epidermidis strain 210 was isolated from the skin swab of a piglet suffering from exudative epidermitis that had been treated with tetracycline. S. aureus 
RN4220 served as recipient strain in protoplast transformation experiments. Both staphylococcal strains were grown overnight at $37^{\circ} \mathrm{C}$ on Blood Agar Base (Gibco) supplemented with sheep blood $7.5 \% \mathrm{w} / \mathrm{v}$. For plasmid preparation $S$. epidermidis 210 was cultivated overnight in Brain Heart Infusion Broth (Merck) supplemented with either tetracycline (Tc) $30 \mu \mathrm{g} / \mathrm{ml}$ or kanamycin $(\mathrm{Km}) 30 \mu \mathrm{g} / \mathrm{ml}$ at $37^{\circ} \mathrm{C}$ on a rotary shaker. Antibiotic resistances were determined by the agar diffusion method [19] on DST Agar (Oxoid) with disks containing tetracycline $30 \mu \mathrm{g}$, kanamycin $30 \mu \mathrm{g}$ and neomycin $30 \mu \mathrm{g}$. Escherichia coli JM107, which served as host for recombinant pBluescript vectors, was grown in Luria Bertani (LB) medium or LB solidified with agar $1.5 \% \mathrm{w} / \mathrm{v}$ [20]. Plasmid pBluescript II $\mathrm{SK}^{+}$was from Stratagene.

\section{Plasmid preparation and Southern blot hybridisation}

A previously described modification of the alkaline lysis procedure [21] was used to prepare plasmid DNA from S. epidermidis 210. Restriction endonucleases (Boehringer) were used according to the manufacturer's recommendations. Transfer of the plasmid fragments from the agarose gels to nitrocellulose membranes followed the capillary blot procedure [20]. An internal 1050-bp BclI fragment of the tet $\mathrm{L}$ gene from plasmid pSTE1 [11] served as tet $\mathrm{L}$ gene probe and an internal 470-bp $A p a \mathrm{I} / B g l \mathrm{II}$ fragment of the plasmid pUB 110 [16] served as aadD gene probe. The gene probes were labelled by the non-radioactive ECL-system (Amersham-Buchler). High stringency hybridisation and signal detection were done with the hybridisation buffer and the detection reagents provided in the ECL kit.

\section{Transformation, cloning and sequence analyses}

Polyethylene glycol-mediated protoplast transformation of the $S$. epidermidis plasmids into the recipient strain $S$. aureus $\mathrm{RN} 4220$ was performed as described previously [21]. The tet $\mathrm{L}$-encoding plasmid pSTE1 [11] and the aadD-encoding plasmid pUB110 [16] were used as controls. Transformants were selected on DM3 regeneration plates [22] supplemented with tetracycline $15 \mu \mathrm{g} / \mathrm{ml}$ or kanamycin $300 \mu \mathrm{g} / \mathrm{ml}$ with incubation for $72 \mathrm{~h}$ at $37^{\circ} \mathrm{C}$. The high concentration of kanamycin was necessary because aminoglycoside antibiotics were partly inactivated by other compounds in the regeneration medium. Transformation of the recombinant $\mathrm{pBluescript} \mathrm{II} \mathrm{SK}^{+}$vectors into $E$. coli JM107 followed the $\mathrm{CaCl}_{2}$ method [23].

Plasmid pSTS7 was cleaved with $B c l \mathrm{I} / B g l \mathrm{II}$ and the resulting three fragments were ligated separately into the Bam HI site of pBluescript II $\mathrm{SK}^{+}$. Sequence analyses were conducted on both strands by the dideoxy chain termination method [24] with the Sequenase version $2.0 \mathrm{kit}$ and $\alpha-{ }^{35} \mathrm{~S} \mathrm{dATP}$ (Amer-
sham-Buchler). Commercially available T3- and T7primers (Stratagene) and three primers obtained from the results of these sequence analyses or derived from the published pUB110 sequence were used to analyse the regions flanking the resistance genes.

\section{Results}

\section{Isolation and identification of plasmid pSTS7}

$S$. epidermidis 210 was resistant to tetracycline, kanamycin and neomycin and harboured a single plasmid of $5.5 \mathrm{~kb}$. Cells of $S$. aureus RN4220 transformed with plasmid DNA from $S$. epidermidis 210 contained a single plasmid of $5.5 \mathrm{~kb}$ and were resistant to tetracycline, kanamycin and neomycin, irrespective of which agent was used for selection. The plasmids were indistinguishable by restriction endonuclease analysis from one another and from that of $S$. epidermidis 210 . This plasmid was designated pSTS7.

The restriction endonuclease map of pSTS7 was similar to the tet $\mathrm{L}$ gene region of the previously described $\mathrm{Tc}^{r}$ plasmid pNS1981 [13, 14], tet L-encoding plasmids from Staphylococcus spp. $[6,11]$ and Bacillus spp. $[12,15]$, and to the aad D gene region of the $\mathrm{Km}^{r} / \mathrm{Nm}^{r} / \mathrm{Ble}^{r}$ plasmid pUB110 from $S$. aureus [16] (Fig. 1). These restriction map homologies were confirmed by Southern blot hybridisation. Three fragments were obtained after $B g l \mathrm{II}$ and $B c l$ I digestion of pSTS7: the tet $\mathrm{L}$ gene probe hybridised to a 1050 -bp $B c l$ I fragment which is of the same size as the internal $B c l \mathrm{I}$ fragment of tet $\mathrm{L}$ genes; the aadD gene probe hybridised to an $A p a \mathrm{I} / B g l$ II fragment of $c$. $470 \mathrm{bp}$.

\section{Sequence analyses of the flanking regions}

The region between the aadD gene and the tet $L$ gene. The nucleotide sequence of the 698-bp BglII/ $B c l$ I fragment is shown in Fig. 2. A comparison with the corresponding sequence of pUB110 revealed identical sequences in the downstream part of the aad D gene, which continued for $c .125 \mathrm{bp}$ downstream of the translational stop codon and was then lost. Comparison of the tet $\mathrm{L}$ gene sequence of pSTS7 with the corresponding part of plasmid pNS1981 revealed identical sequences in the upstream part of the tet $\mathrm{L}$ stuctural gene and the tet $\mathrm{L}$ translational attenuator. Sequence homology between the pSTS7 and pNS1981 sequences broke down $c .100 \mathrm{bp}$ upstream of the translational start codon for the tet $\mathrm{L}$ leader peptide. Thus, there was substantial sequence homology between pSTS7 and pUB110 from positions 1 to 305 and between pSTS7 and pNS1981 from positions 280 to 698 (Fig. 2). The 26-bp region located between positions 280 and 305 exhibited $88.5 \%$ nucleotide 
pNS1981

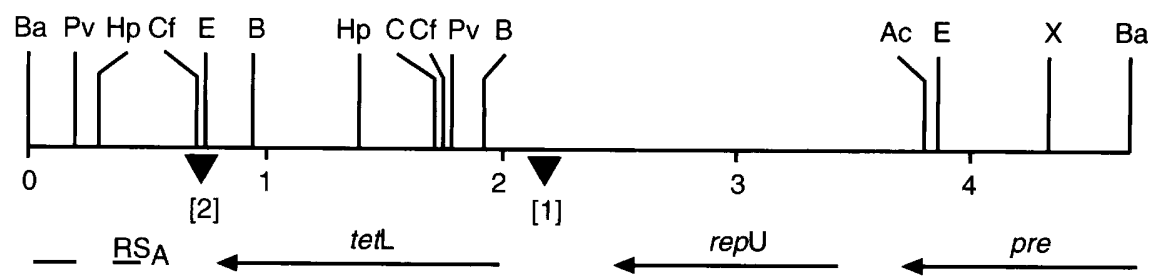

pSTS7

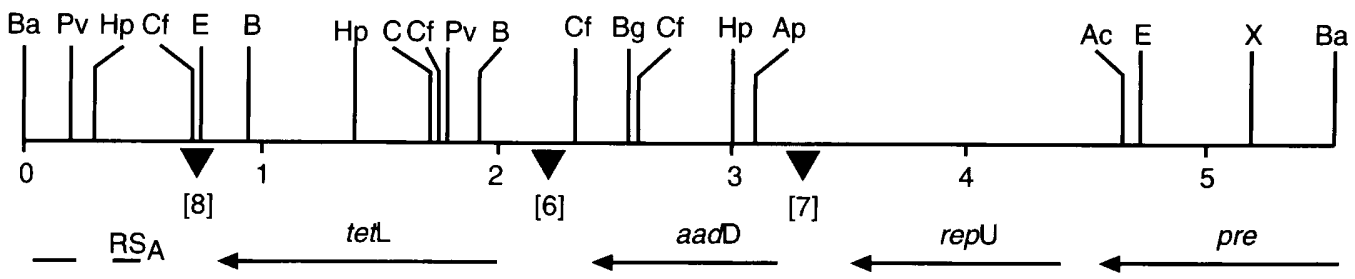

pUB110

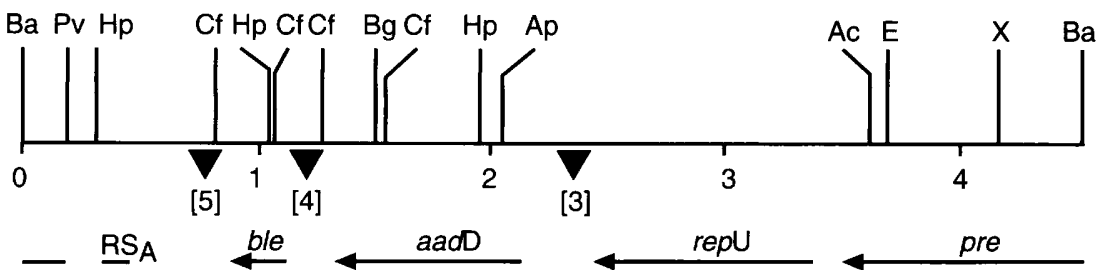

Fig. 1. Comparison of the restriction maps of the plasmids pNS1981 from B. subtilis, pUB110 from $S$. aureus and pSTS7 from $S$. epidermidis. Restriction endonuclease cleavage sites are abbreviated as follows: Ac (AccI), Ap (ApaI), $\mathrm{B}(B c l \mathrm{I}), \mathrm{Ba}(B a m \mathrm{HI}), \mathrm{Bg}(B g l \mathrm{II}), \mathrm{C}(C l a \mathrm{I}), \mathrm{Cf}(C f o \mathrm{I}), \mathrm{E}(E c o \mathrm{RI}), \mathrm{Hp}(H p a \mathrm{II}), \mathrm{Pv}(P v u \mathrm{II})$, and X $(X b a \mathrm{I})$. A distance scale in $\mathrm{kb}$ is shown below each map; the arrows indicate the extent and the direction of transcription of the tet $\mathrm{L}$, aad $\mathrm{D}$, rep $\mathrm{U}$, pre and ble reading frames. The location of the recombination site $\mathrm{A}\left(\mathrm{RS}_{A}\right)$ is shown in all three restriction maps. Important areas with respect to recombination processes (Fig. 5) are numbered as [1]-[8].

sequence identity to the corresponding pUB110 section and $92.3 \%$ nucleotide sequence identity to the corresponding region of pNS1981.

The regions downstream of the repU genes. The plasmids pUB110, pSTS7 and pNS1981 exhibited identical sequences in the downstream part of their rep $\mathrm{U}$ genes. Although the sequences downstream of the rep $\mathrm{U}$ coding region were indistinguishable in pUB 110 and pSTS7, the sequence identity stopped in pNS1981 $16 \mathrm{bp}$ downstream of the translational stop codon of the rep $\mathrm{U}$ gene (Fig. 3).

The regions downstream of the tetL gene and the ble gene. The tet $\mathrm{L}$ gene of pSTS7 showed no sequence homology to any part of the pUB110 sequence, but perfect sequence homology with pNS1981. Homology between pSTS7 and the part of the pUB110 sequence downstream of the bleomycin resistance gene ble started c. $84 \mathrm{bp}$ downstream of the tet $\mathrm{L}$ coding region (Fig. 4).

\section{Discussion}

The presence of structurally related antibiotic resistance plasmids in a wide variety of staphylococcal species and in bacilli indicated the occurrence of interspecies and intergenus transfer events $[6,11,25]$.
The exchange of antibiotic resistance plasmids might be furthered by the presence of the antibiotics used for therapeutic or prophylactic purposes [11]

When transferred into new bacterial hosts, resistance plasmids, such as the aadD-encoding $\mathrm{Km}^{r} / \mathrm{Nm}^{r} / \mathrm{Ble}^{r}$ plasmid pUB110 or the tetL-encoding $\mathrm{Tc}^{r}$ plasmid pNS1981, have to face host-specific restriction systems that might protect the host cell from foreign DNA. Other problems that might arise are a general inability to replicate in the new host or the incompatibility of the new plasmid with plasmids already present. These problems can be circumvented by integration of all or part of the plasmid into the chromosomal DNA of the host cell, or by interplasmid recombination of the new resistance plasmid with other plasmids of the new host.

Chromosomal integration has been described for plasmid pUB 110 and for tet $\mathrm{L}$-encoding plasmids. In the case of the $\mathrm{Km}^{r} / \mathrm{Nm}^{r} / \mathrm{Ble}^{r}$ plasmid pUB110, integration into the mec region of the chromosome of methicillin-resistant $S$. aureus is mediated by the insertion element IS257 [26]. In contrast, little is known about the way a tet $\mathrm{L}$ gene almost identical to that of plasmid pNS1981 got into the $B$. subtilis chromosome [27].

Several small S. aureus plasmids undergo site-specific 
$\mathrm{Bg} \underline{\mathrm{III} / \mathrm{Mb} O \mathrm{I}}$

$\begin{array}{lllllllllllllllllllllllllllll}P & S & G & Y & D & H & L & C & O & F & V & M & S & G & Q & L & S & D & S & E & K\end{array}$

pUB110 : AGATCTTCCTTCAGGTTATGACCATCTGTGCCAGTTCGTAATGTCTGGTCAACTTTCCGACTCTGAGAAA

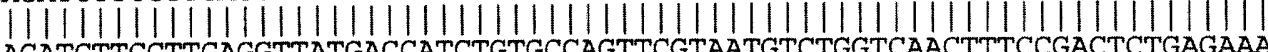

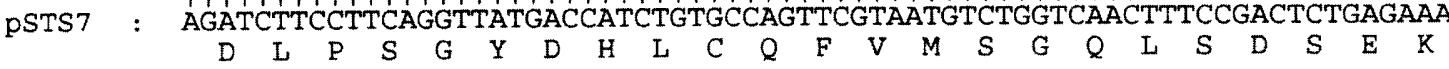

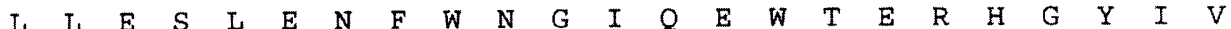
pUB110 : CTTCTGGAATCGCTAGAGAATTTCTGGAATGGGATTCAGGAGTGGACAGAACGACACGGATATATAGTG

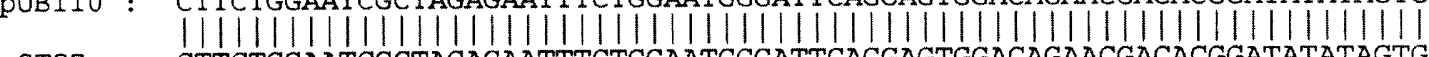

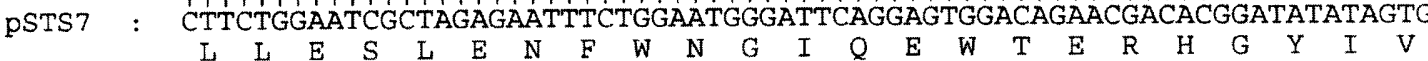

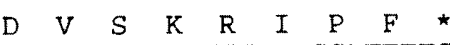

pUB110 : GATGTGTCAAAACGCATACCATTTTGAACGATGACCTCTAATAATTGTTAATCATGTTGGTTACGTATTTA : |||||||||||||||||||||||||||||||||||||||||||||||||||||||||||||||||||||| pSTS7 : GATGTGTCAAAACGCATACCATTTTGAACGATGACCTCTAATAATTGTTAATCATGTTGGTTACGTATTTA $\begin{array}{llllllll}D & V & S & K & R & I & P & F \\ \text { end } & \text { a }\end{array}$

CfOI

pUB110 : TTAACTTCTCCTAGTATTAGTAATTATCATGGCTGTCATGGCGCATTAACGGAATAAAGGGTGTGC - TT

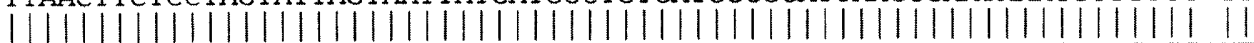
pSTS7 : TTAACTTCTCCTAGTATTAGTAATTATCATGGCTGTCATGGCGCATTAACGGAATAAAGGGAGTGCTTT

pUB110 : AAATCGGGCCAT-TTTGC-GTAATAAGAAAAAGGATTAATTATGAGCGAATTGAATTAATAATAAGGTAAT

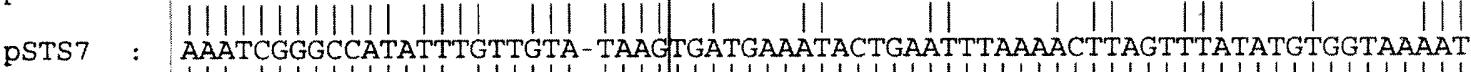
pNS1981: AAA-CGGGCCATATT-GTTGTA-TAAGTGATGAAATACTGAATTTAAAACTTAGTTTATATGTGGTAAAAT

$$
\begin{array}{lllllllllllllllllllll}
M & K & C & N & E & C & N & R & V & Q & L & K & E & G
\end{array}
$$

pSTS7 : GTTTTAATCAAGTTTAGGAGGAATTAATTATGAAGTGTAATGAATGTAACAGGGTTCAATTAAAAGAGGGA pNS1981: GTTTTAATCAAGTTTAGGAGGAATTAATTATGAAGTGTAATGAATGTAACAGGGTTCAATTAAAAGAGGGA $\begin{array}{llllllllllllllllllll}M & K & C & N & E & C & N & R & V & Q & L & K & E & G\end{array}$ start tet $(L)$ leader

S V $\quad S \quad L \quad T \quad L \quad$ *

$\begin{array}{lllllllllll}V & N & T & S & Y & S\end{array}$

pSTS7 : AGCGTATCATTAACCCTATAAACTACGTCTGCCCTCATTATTGGAGGGTGAAATGTGAATACATCCTATTCA pNS1981:

start tet $(\mathrm{L})$

$\begin{array}{llllllllllllllllllllllll}Q & S & N & L & R & H & N & Q & I & L & I & W & L & C & I & L & S & F & F & S & V & L & N & E\end{array}$ CAATCGAATTTACGACACAACCAAATTTTAATTTGGCTTTGCATTTTATCTTTTTTTAGCGTATTAAATGAA

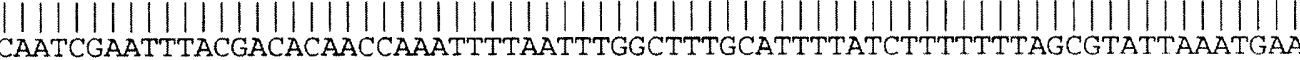

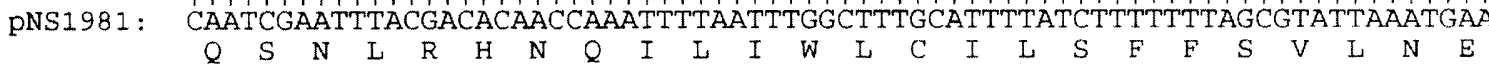

$\begin{array}{llllllllllllllllllllllll}M & V & L & N & V & S & L & P & D & I & A & N & D & F & N & K & P & P & A & S & T & N & W & V\end{array}$ pSTS7 : ATGGTTTTGAACGTCTCATTACCTGATATTGCAAATGATTTTAATAAACCACCTGCGAGTACAAACTGGGTG

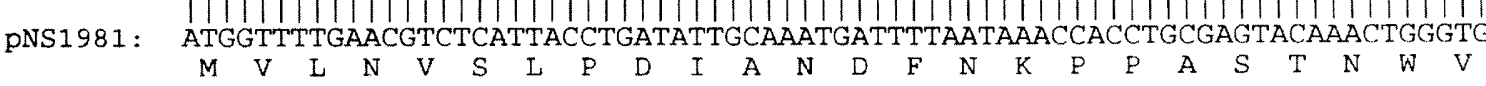
636

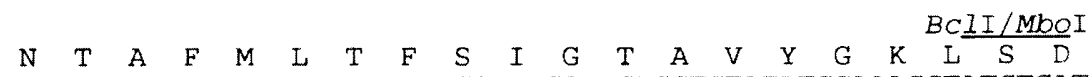

pSTS7 : AACACAGCCTTTATGTTAACCTTTTCCATTGGAACAGCTGTATATGGAAAGCTATCTGATCA

pNS1981: AACACAGCCTTTATGTTAACCTTTTCCATTGGAACAGCTGTATATGGAAAGCTATCTGATCA

$\begin{array}{llllllllllllllllllll}N & T & A & F & M & \text { L } & \text { T } & F & \text { S } & \text { I } & G & \text { T } & \text { A } & \text { V } & \text { Y } & \text { G } & \text { K } & \text { L } & S & \text { D }\end{array}$

Fig. 2. Nucleotide sequence of the $698 \mathrm{bp} B g l \mathrm{II} / \mathrm{Bcl}$ I fragment of plasmid pSTS7 (region [6]) which comprises the region between the end of the $a a d \mathrm{D}$ gene and the start of the tet $\mathrm{L}$ gene. The vertical bars ( $\mid$ ) indicate identical bases in comparison to the corresponding sequences of the aadD gene of plasmid pUB110 (region [4]) and the tet $\mathrm{L}$ gene of plasmid pNS1981 (region [1]). The amino-acid sequences of the aad D, tet $\mathrm{L}$ leader and tet $\mathrm{L}$ reading frames are displayed in the single letter code. Asterisks $\left({ }^{*}\right)$ mark translational stop codons. Important restriction endonuclease cleavage sites with respect to Fig. 1 are indicated. The region that is thought to be involved in co-integrate formation is boxed. 


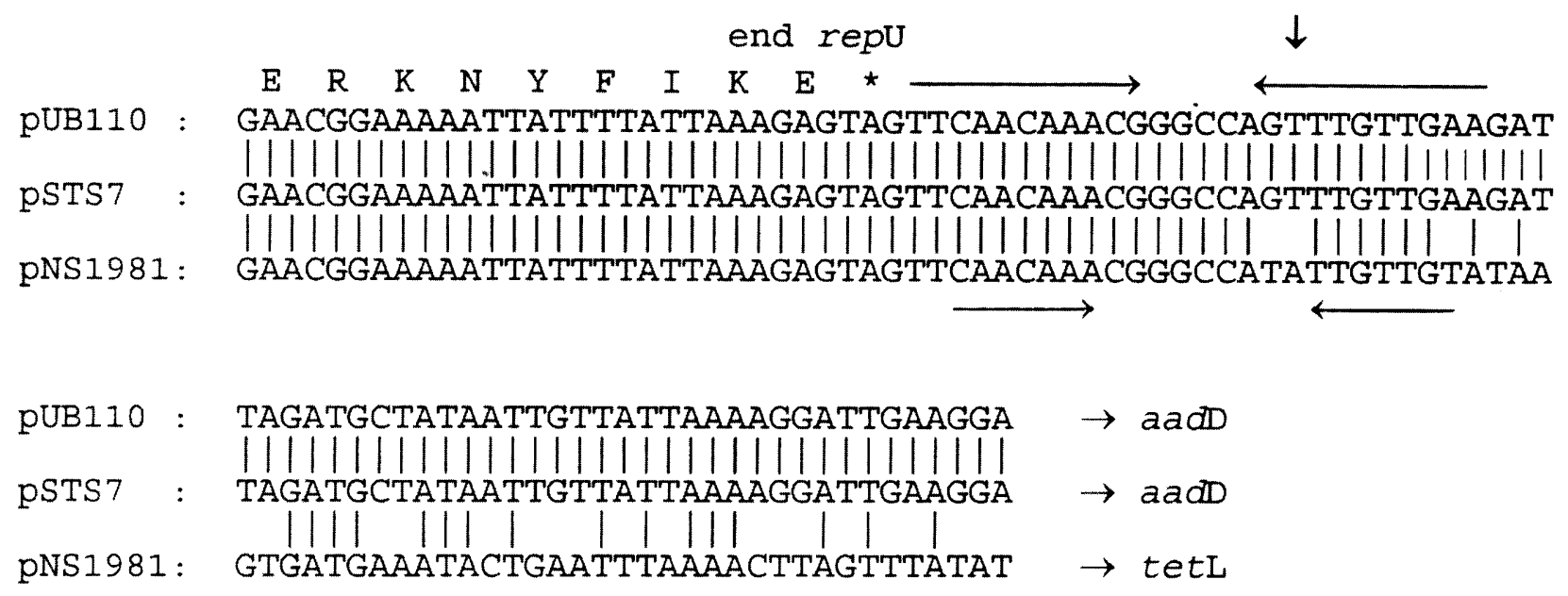

Fig. 3. Comparison of the sequences preceding the aadD genes in pUB110 (region [3]) and pSTS7 (region [7]) as well as the tet $\mathrm{L}$ gene in pNS1981 (region [1]). The vertical arrow $(\downarrow)$ indicates a previously described junction point between homologous and non-homologous regions in the plasmids pNS1981 and pUB110. The inverted repeats downstream of the rep genes are indicated by arrows $(\rightarrow \leftarrow)$.

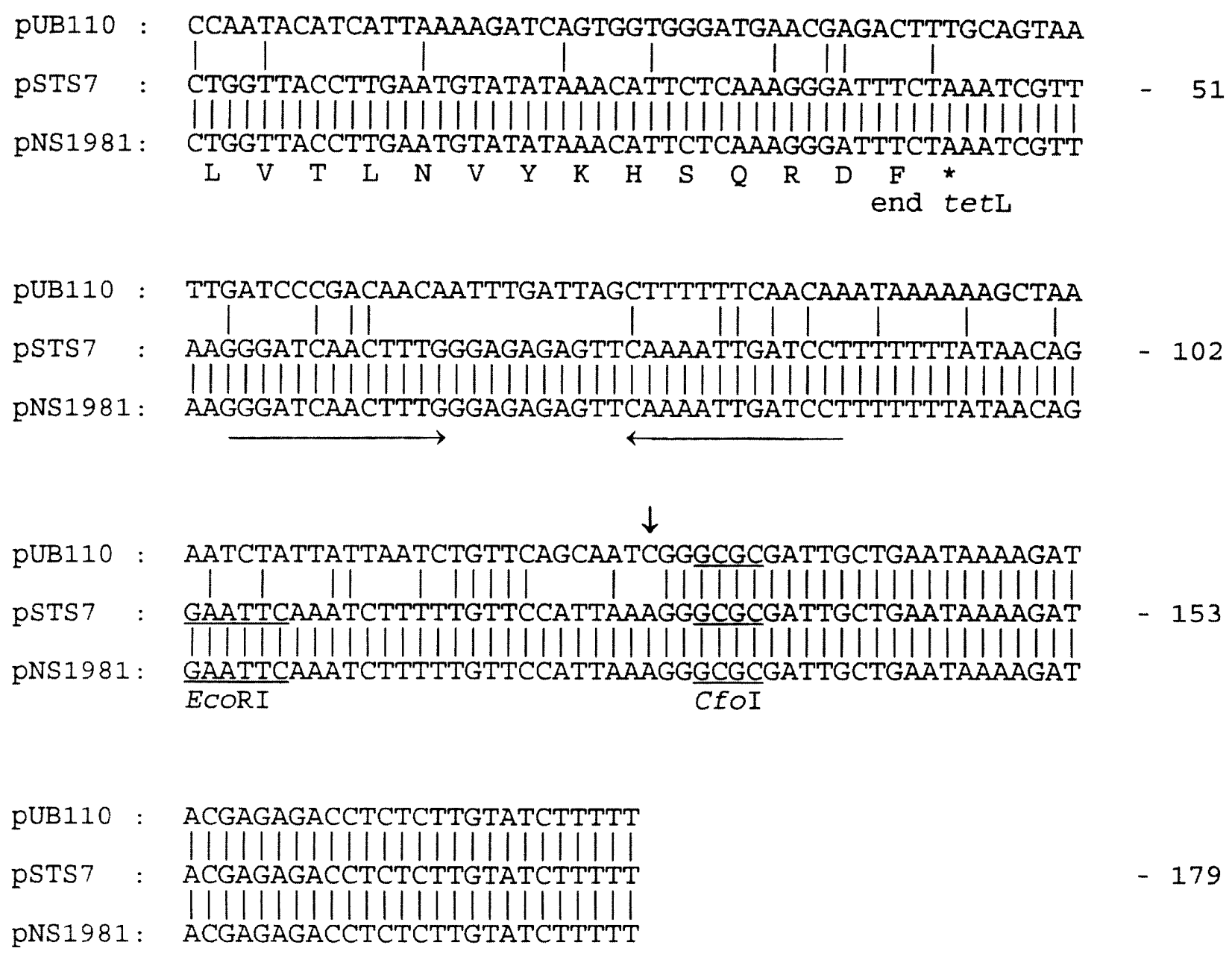

Fig. 4. Comparison of the nucleotide sequences downstream of the tet L genes in pNS1981 (region [2]) and pSTS7 (region [8]) with the corresponding sequence of pUB110 (region [5]). The inverted repeated sequences that represent the rho-independent transcriptional terminator of the tet $\mathrm{L}$ gene are indicated by arrows $(\rightarrow \leftarrow)$. The amino-acid sequence of the carboxyterminal part of the TetL protein is given in the one-letter code. Important restriction endonuclease cleavage sites with respect to Fig. 1 are indicated. The vertical arrow $(\downarrow)$ indicates a previously described junction point between homologous and non-homologous regions in the plasmids pNS1981 and pUB110. 


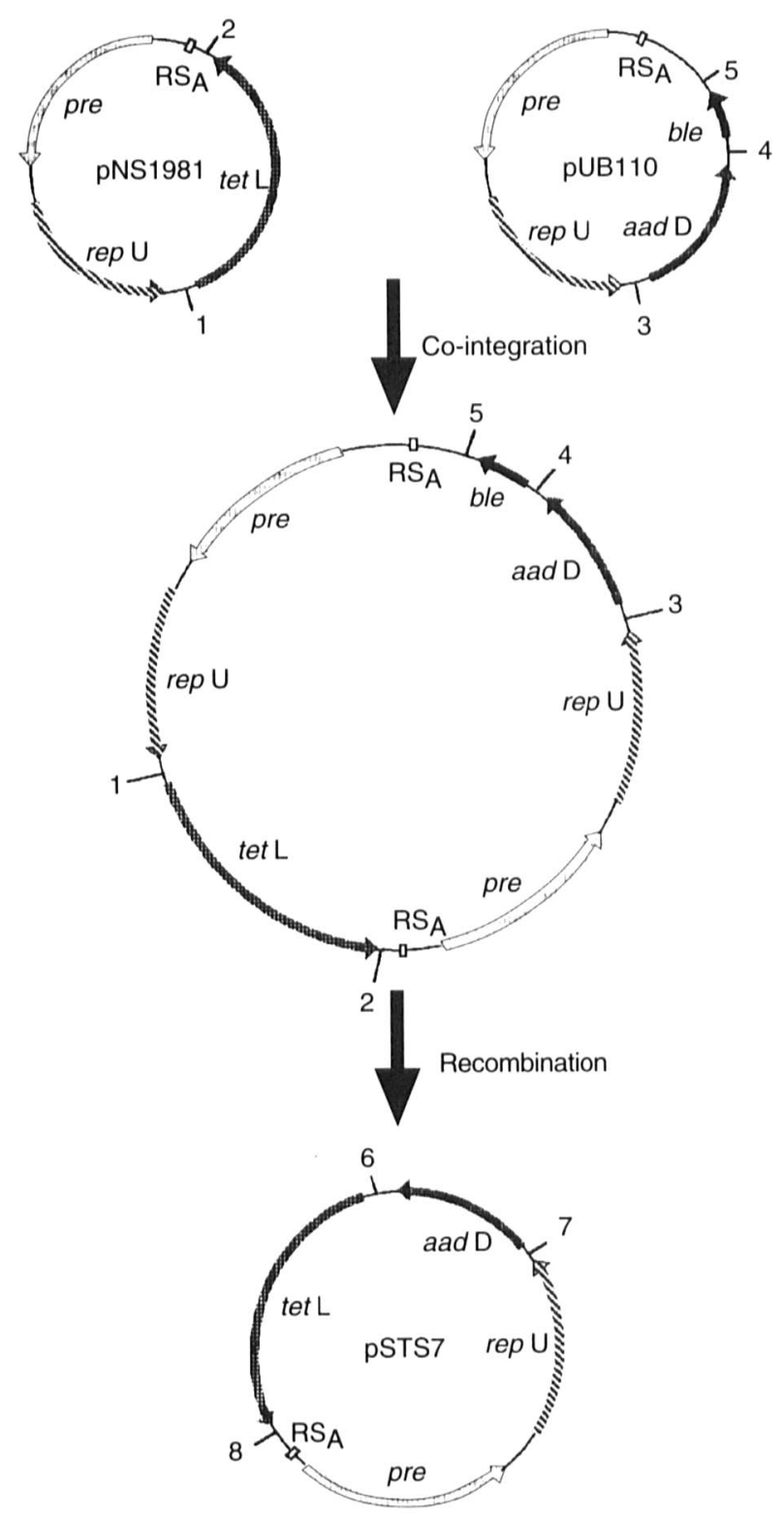

Fig. 5. Model to explain the derivation of plasmid pSTS7 from pNS1981- and pUB110-like precursors by $\mathrm{RS}_{A^{-}}$ mediated co-integrate formation and subsequent intraplasmid homologous recombination.

interplasmid recombination with formation of stable co-integrates [28]. Recombination sites $\mathrm{RS}_{A}$ and $\mathrm{RS}_{B}$ are used most often $[29,30]$, but there are also small areas of sequence homology that serve for homologous recombination of staphylococcal plasmids mediating chloramphenicol and streptomycin resistance [31] as well as chloramphenicol and tetracycline resistance [30].

Co-integrate formation between plasmids of the pUB110 and pNS1981 type allows a possible explanation for the development of plasmid pSTS7. Previous investigations described the aadD-encoding $\mathrm{Km}^{r} / \mathrm{Nm}^{r}$ / $\mathrm{Ble}^{r}$ plasmid pUB110 [16] and the tet L-encoding $\mathrm{Tc}^{r}$ plasmid pNS1981 $[13,14]$ as homologous rep $\mathrm{U}$ based replicons that harboured different resistance gene cassettes. However, an identical rep gene assigned the respective plasmids to the same incompatibility group. Normally, plasmids of the same incompatibility group cannot be maintained stably together in the same bacterial cell [32], but if recombination systems are intact and the selective pressure is strong, incompatible plasmids can be accommodated by forming a hybrid plasmid consisting of parts from both individual plasmids [33]. Both plasmids, pUB110 and pNS1981, had a recombination site $\mathrm{A}\left(\mathrm{RS}_{A}\right)$ and carried a pre gene that encoded a recombinase that acts on $\mathrm{RS}_{A}$. Thus, the presence of plasmid-encoded recombination systems allowed recombination to occur independently of the host cell-specific recombination systems. Cointegrate formation via $\mathrm{RS}_{A}$ might result in a hybrid plasmid that carried two rep $\mathrm{U}$ and pre genes, two $\mathrm{RS}_{A}$ sites and the resistance genes tet $\mathrm{L}$, aad $\mathrm{D}$ and ble (Fig. 5). Since small staphylococcal plasmids replicate via a single-stranded intermediate [34], they are prone to recombination in that state of replication, provided that there are sufficient structural homologies [34]. Thus, the hybrid plasmid could undergo intraplasmid homologous recombination favoured by almost identical sequences flanking the resistance genes in pNS1981 and in pUB110. It is suggested that homologous recombination may have occurred between region [1] in pNS1981 and region [4] in pUB110 (to give rise to region [6] in pSTS7; Fig. 2, boxed area). Such a recombination event would replace the ble gene and its downstream sequences with the tet $\mathrm{L}$ gene and its associated regulatory sequences (Fig. 5). Since the sequences downstream of the ble gene in pUB110 and those downstream of the tet $\mathrm{L}$ reading frame in pNS1981 are identical, this recombination allowed the exchange of the ble gene by a tet $\mathrm{L}$ gene cassette.

The $S$. epidermidis strain 210 from which pSTS7 was isolated, was obtained from a pig that had received tetracyclines for therapeutic purposes. This could explain the selective pressure that favoured the exchange of $\mathrm{Tc}^{r}$ plasmids within a staphylococcal population. Since pUB110-like $\mathrm{Km}^{r} / \mathrm{Nm}^{r} / \mathrm{Ble}^{r}$ plasmids as well as pNS1981-like $\mathrm{Tc}^{r}$ plasmids have been shown to be present in the staphylococcal gene pool and have been identified in different epidemiologically unrelated, staphylococcal isolates $[5,6]$, it is unlikely that a plasmid, such as pSTS7, has developed de novo in the $S$. epidermidis strain 210 . It is more likely to have been derived from putative pUB110 and pNS1981 plasmids as a consequence of recombination events that might be favoured by the incompatibility properties of the plasmids, the presence of plasmid recombination systems, and the selective pressure of the antibiotics used.

The nucleotide sequences presented in this manuscript have been submitted to GenBank and assigned accession number U35229.

The authors thank the British Council and the German Academic Exchange Service (DAAD) for financial support of this collaboration. 


\section{References}

1. Levy SB. Resistance to the tetracyclines. In: Bryan LE (ed) Antimicrobial drug resistance. Orlando, Academic Press. 1984: 191-240.

2. Chopra I, Hawkey PM, Hinton M. Tetracyclines, molecular and clinical aspects. $J$ Antimicrob Chemother 1992; 29: 245-277.

3. Cooksey RC, Baldwin JN. Relatedness of tetracycline resistance plasmids among species of coagulase-negative staphylococci. Antimicrob Agents Chemother 1985; 27: 234 238.

4. Schwarz S, Cardoso M, Grölz-Krug S, Blobel H. Common antibiotic resistance plasmids in Staphylococcus aureus and Staphylococcus epidermidis from human and canine infections. Zentralbl Bakteriol 1990; 273: 369-377.

5. Lyon BR, Skurray R. Antimicrobial resistance of Staphylococcus aureus: genetic basis. Microbiol Rev 1987; 51: 88-134.

6. Schwarz S, Noble WC. Tetracycline resistance genes in staphylococci from the skin of pigs. J Appl Bacteriol 1994; 76: $320-326$

7. Khan SA, Novick RP. Complete nucleotide sequence of pT181, a tetracycline-resistance plasmid from Staphylococcus aureus. Plasmid 1983; 10: 251-259.

8. Mojumdar M, Khan SA. Characterization of the tetracycline resistance gene of plasmid pT181 of Staphylococcus aureus. $J$ Bacteriol 1988; 170: 5522-5528.

9. Guay GG, Khan SA, Rothstein DM. The tet $(\mathrm{K})$ gene of plasmid pT181 of Staphylococcus aureus encodes an efflux protein that contains 14 transmembrane helices. Plasmid 1993; 30: $163-166$

10. Levy SB. Tetracycline resistance determinants are widespread. ASM News 1988; 54: 418-421.

11. Schwarz S, Cardoso M, Wegener HC. Nucleotide sequence and phylogeny of the tet $(\mathrm{L})$ tetracycline resistance determinant encoded by the plasmid pSTE1 from Staphylococcus hyicus. Antimicrob Agents Chemother 1992; 36: 580-588.

12. Hoshino T, Ikeda T, Tomizuka N, Furukawa K. Nucleotide sequence of the tetracycline resistance gene of pTHT15, a thermophilic Bacillus plasmid: comparison with staphylococcal $\mathrm{Tc}^{R}$ controls. Gene 1985; 37: 131-138.

13. Shishido K, Tanaka Y. A restriction map of Bacillus subtilis tetracycline-resistance plasmid pNS1981. Plasmid 1984; 12: 65-66.

14. Sakaguchi $R$, Shishido $K$, Hoshino $T$, Furukawa $K$. The nucleotide sequence of the tetracycline resistance gene of plasmid pNS1981 from Bacillus subtilis differs from pTHT15 from a thermophilic Bacillus by two base pairs. Plasmid 1986; 16: $72-73$

15. Palva A, Vidgren $G$, Simonen $M$, Rintala $H$, Laamanen $P$. Nucleotide sequence of the tetracycline resistance gene of pBC16 from Bacillus cereus. Nucleic Acids Res 1990; 18: 1635 .

16. McKenzie T, Hoshino T, Tanaka T, Sueoka N. The nucleotide sequence of pUB 110: some salient features in relation to replication and its regulation. Plasmid 1986; 15: 93-103.

17. McKenzie T, Hoshino T, Tanaka T, Sueoka N. A revision of the nucleotide sequence and functional map of pUB 110 .
Plasmid 1987; 17: 83-85.

18. Sakaguchi R, Shishido K. A unique DNA structure of the junction of homologous and non-homologous regions between tetracycline-resistance plasmid pNS1981 and kanamycin-resistance plasmid pUB110. Nucleic Acids Res. 1987; 15: 7202.

19. Barry A, Thornsberry C. Susceptibility tests: diffusion test procedures. In: Lennette EH, Balows A, Hausler WH, Shadomy HJ (eds) Manual of clinical microbiology, 4th edn. Washington DC, American Society for Microbiology. 1985: 978-987.

20. Sambrook J, Fritsch EF, Maniatis T. Molecular cloning: a laboratory manual, 2nd edn. Cold Spring Harbor, NY, Cold Spring Harbor Laboratory. 1989

21. Schwarz S, Cardoso M, Blobel H. Plasmid-mediated chloramphenicol resistance in Staphylococcus hyicus. $J$ Gen Microbiol 1989; 135: 3329-3336.

22. Chang S, Cohen SN. High frequency transformation of Bacillus subtilis protoplasts by plasmid DNA. Mol Gen Genet 1979; 168: $111-115$.

23. Dagert $M$, Ehrlich SD. Prolonged incubation in calcium chloride improves the competence of Escherichia coli cells. Gene 1979 ; 6: 23-28.

24. Sanger F, Nicklen S, Coulson AR. DNA sequencing with chain-terminating inhibitors. Proc Natl Acad Sci USA 1977; 74: $5463-5467$.

25. Polak J, Novick RP. Closely related plasmids from Staphylococcus aureus and soil bacilli. Plasmid 1982; 7: 152-162.

26. Stewart PR, Dubin DT, Chikramane SG, Inglis B, Matthews PR, Poston SM. IS257 and small plasmid insertions in the mec region of the chromosome of Staphylococcus aureus. Plasmid 1994; 31: $12-20$.

27. Sakaguchi R, Amano H, Shishido K. Nucleotide sequence homology of the tetracycline-resistance determinant naturally maintained in Bacillus subtilis Marburg 168 chromosome and the tetracycline-resistance gene of $B$. subtilis plasmid pNS1981. Biochim Biophys Acta 1988; 950: 441-444.

28. Novick RP. Staphylococcal plasmids and their replication. Annu Rev Microbiol 1989; 43: 537-565.

29. Gennaro ML, Kornblum J, Novick RP. A site-specific recombination function in Staphylococcus aureus plasmids. $J$ Bacteriol 1987; 169: 2601-2610.

30. Novick RP, Projan SJ, Rosenblum W, Edelman I. Staphylococcal plasmid cointegrates are formed by host- and phagemediated general rec systems that act on short regions of homology. Mol Gen Genet 1984; 195: 374-377.

31. Schwarz S, Noble WC. Structure and putative origin of a plasmid from Staphylococcus hyicus that mediates chloramphenicol and streptomycin resistance. Lett Appl Microbiol 1994; 18: 281-284.

32. Novick RP. Plasmid incompatibility. Microbiol Rev 1987; 51: 381-395.

33. Miller RV, Levy SB. Horizontal gene transfer in relation to environmental release of genetically engineered microorganisms. In: Levy SB, Miller RV (eds) Gene transfer in the environment. New York, McGraw-Hill. 1989: 405-420.

34. Gruss A, Ehrlich SD. The family of highly interrelated singlestranded deoxyribonucleic acid plasmids. Microbiol Rev 1989; 53: $231-241$ 